\title{
Venom immunotherapy and pregnancy
}

\author{
Krzysztof Pałgan, Magdalena Żbikowska-Götz, Elżbieta Chrzaniecka, Zbigniew Bartuzi
}

Department of Allergology, Clinical Immunology and Internal Diseases, Ludwik Rydygier Collegium Medicum in Bydgoszcz, Nicolaus Copernicus University in Torun, Poland

Adv Dermatol Allergol 2018; XXXV (1): 90-92

DOI: https://doi.org/10.5114/ada.2018.73168

\begin{abstract}
Introduction: The efficiency of venom immunotherapy (VIT) has been well documented by many studies. However, the most important for VIT is safety, particularly for a pregnant woman and a fetus.

Aim: To establish the influence of continuation of VIT on pregnant women and offspring.

Material and methods: The 6 women became pregnant during a specific immunotherapy. We retrospectively analyzed the influence of the immunotherapy on any complications for the pregnant women and their infants.

Results: Of the 6 patients who participated in this study, four had hyperemesis gravidarum, nausea, and heartburn, and two of them had gestational diabetes mellitus symptoms, typical of pregnancy. The observation indicated that VIT was safe for the pregnant women and their offspring.

Conclusions: The VIT is an appropriate therapeutic method for most patients with severe anaphylactic reactions after a hymenoptera sting. The observation indicated that VIT is safe for pregnant women and for their infants.
\end{abstract}

Key words: venom immunotherapy, pregnancy.

\section{Introduction}

The first description of an allergen-specific immunotherapy was published by Leonard Noon in 1911. The report showed that a subcutaneous injection of increasing doses of a grass pollen extract led to the tolerance of these pollens by sensitive patients [1]. Hymenoptera, including honeybee (Apis mellifera) and wasp (Vespula germanica and Vespula vulgaris) stings, usually can cause normal responses such as transient pain, itching, and swelling, but approximately $5 \%$ of the general population can develop severe, systemic, life-threatening reactions [2, 3].

Venom immunotherapy (VIT) was established in the 1970s. Venom immunotherapy protects against fatal anaphylaxis and prevents $90-95 \%$ of all reactions to stings. The recommended duration of the venom immunotherapy is 5 years, and this period is considered to be sufficient for allergic patients [4]. A special group of patients are women of childbearing age and pregnancy. According to the EEACI recommendations, the continuation of VIT is not a contra-indication during pregnancy [5].

\section{Aim}

This study examines the influence of VIT on any problems during pregnancy and the influence on offspring.

\section{Material and methods}

Six women with a history of a systemic reaction of grades III and IV according to Ring and Messmer [6] to a Vespidae (Vespula germanica, Vespula vulgaris) sting were included in the VIT and the study retrospectively. Only 1 patient was sensitized to airborne and cat allergens. Table 1 shows the characteristics of the tested group.

The blood for the examination was collected from ulnar veins into a test tube with lithium heparin of a final concentration of $10 \mathrm{U} / \mathrm{ml}$ using a closed Vacutainer system, and on a clot to a test tube without anticoagulants. The total IgE and aslgE were measured using enzyme immunoassay (EIA) Hycor TM kits (Hycor, United Kingdom). Additionally, in all examined patients the following were assessed: the level of serum tryptase by fluorescence enzyme immunoassay (FEIA) using ImmunoCAP tryptase kits on UNICAP 100. All tests were performed according to the producer's instructions.

The venom immunotherapy was performed with Venomenhal Wasp (Hal Allergy) (Table 2).

\section{Results}

In total, 6 patients with an average age of 31 to 17 years, were treated with wasp venom immunotherapy.

Address for correspondence: Krzysztof Pałgan MD, Department of Allergology, Clinical Immunology and Internal Diseases, Collegium Medicum, Nicolaus Copernicus University, 75 Ujejskiego St, 85-168 Bydgoszcz, Poland, phone: +48 5236554 16, fax: +48 5234840 76, e-mail: palgank@wp.pl Received: 27.08.2016, accepted: 28.11.2016. 
The mean time to fertilization after VIT initiation was $26.5 \pm 15.3$ months.

Of the 6 pregnant women receiving VIT, 4 had hy peremesis gravidarum, nausea, and heartburn, and 2 of them had gestational diabetes mellitus symptoms, typical of pregnancy. All offspring were normal and in good condition. The mean birth weight was $3.68 \pm 0.57 \mathrm{~kg}$ (Table 3).

\section{Discussion}

Allergy to insect stings and systemic anaphylactic reactions are most often IgE mediated [7]. Severe systemic anaphylaxis is a known cause of respiratory and cardiovascular symptoms and could lead to shock and cardiac arrest [8]. According to the Hymenoptera Venom Allergy (HVA) experts, adrenaline is the mainstay of therapy to halt the progression of anaphylaxis and to reverse potentially life-threatening, cardiopulmonary manifestations [9]. Anaphylaxis and maternal hypoxemia lead to placenta vasoconstriction and uterine contractions, and are a known cause of fetal abnormalities, premature labor and consequently maternal morbidity or even mortality [10]. The side effects of treatment with adrenaline also could be dangerous for pregnant women as well as for a fetus [11].
Table 1. Characteristics of the women $(n=6)$ who underwent VIT

\begin{tabular}{ll}
\hline Parameter & Characteristics \\
\hline Age $[$ years $]$ & $31.17 \pm 3.97(28-36)$ \\
\hline BMI $\left[\mathrm{kg} / \mathrm{m}^{2}\right]$ & $24.02 \pm 4.15(21.2-30.4)$ \\
\hline Grade of anaphylactic reaction & $\begin{array}{l}\mathrm{III}-2 \text { patients } \\
\text { IV }-4 \text { patients }\end{array}$ \\
\hline $\begin{array}{l}\text { Other allergic sensitization } \\
\text { positive skin-prick test and } \\
\text { symptoms) }\end{array}$ & $\begin{array}{l}\text { Only } 1 \text { patient was sensitized } \\
\text { to a tree, grass pollen, and cat } \\
\text { allergens }\end{array}$ \\
\hline \begin{tabular}{l} 
gE before VIT: \\
\hline Total
\end{tabular} & \begin{tabular}{l}
$71 \pm 53.67 \mathrm{KU} / \mathrm{l}$ \\
\hline Wasp specific (aslgE)
\end{tabular} \\
\hline Blood baseline tryptase & $\begin{array}{l}\text { Mastocytosis was excluded, } \\
\text { the tryptase levels were } \\
\text { normal }\end{array}$ \\
\hline
\end{tabular}

Table 2. Protocol for venom immunotherapy. Rush method for initiation of the therapy [5]

\section{Day 1: $0.1 \mu \mathrm{g}, 1.0 \mu \mathrm{g}, 2 \mu \mathrm{g}, 4 \mu \mathrm{g}, 8 \mu \mathrm{g}, 10 \mu \mathrm{g}, 20 \mu \mathrm{g} 7$ s.c.} injections at $30 \mathrm{~min}$ intervals

Day 2: $40 \mu \mathrm{g}, 60 \mu \mathrm{g}, 80 \mu \mathrm{g}$ and $100 \mu \mathrm{g}$ fore s.c. injections at 30-60 min intervals

and continuation $100 \mu g$ s.c. monthly

Table 3. Pregnancy complications related to maternal and fetal birth status

\begin{tabular}{|c|c|c|}
\hline $\begin{array}{l}\text { VIT duration before } \\
\text { fertilization [months] }\end{array}$ & Pregnancy complications & Fetal birth status \\
\hline 11 & Heartburn & $\begin{array}{c}\text { APGAR: } 9 \\
\text { Gestational age at birth: } 41 \text { weeks } \\
\text { Birth weight: } 4.6 \mathrm{~kg} \\
\text { Cesarean delivery because of fetus weight and small maternal } \\
\text { pelvis making vaginal birth impossible }\end{array}$ \\
\hline 16 & Hyperemesis gravidarum & $\begin{array}{l}\text { APGAR: } 10 \\
\text { Gestational age at birth: } 40 \\
\text { Birth weight: } 3.56 \mathrm{~kg} \\
\text { Benign hip dysplasia }\end{array}$ \\
\hline 41 & Cervical insufficiency & $\begin{array}{l}\text { APGAR: } 10 \\
\text { Gestational age at birth: } 38 \\
\text { Birth weight: } 3.3 \mathrm{~kg}\end{array}$ \\
\hline 45 & $\begin{array}{l}\text { Gestational diabetes mellitus treated } \\
\text { with diet }\end{array}$ & $\begin{array}{c}\text { APGAR: } 10 \\
\text { Gestational age at birth: } 38 \\
\text { Birth weight: } 3.08 \mathrm{~kg}\end{array}$ \\
\hline 34 & $\begin{array}{l}\text { Gestational diabetes mellitus treated } \\
\text { with diet and heartburn }\end{array}$ & $\begin{array}{l}\text { APGAR: } 10 \\
\text { Gestational age at birth: } 40 \\
\text { Birth weight: } 4.16 \mathrm{~kg}\end{array}$ \\
\hline 12 & Nausea & $\begin{array}{l}\text { APGAR: } 10 \\
\text { Gestational age at birth: } 40 \\
\text { Birth weight: } 3.4 \mathrm{~kg}\end{array}$ \\
\hline
\end{tabular}


A specific venom immunotherapy is an important and recommended method of the curative treatment of patients with a high risk of a bad outcome [12]. Venom immunotherapy is effective and lessens the risk of a systemic reaction, prevents morbidity and mortality and improves the quality of life. The advised duration of VIT is 5 years. In the case of young women in the reproductive period, there is high probability of gestation $[10,13]$.

These studies confirm an earlier observation that VIT is safe for pregnant women. The data presented show that all the newborns were in a good condition. All babies were without congenital defects or fetal malformations and were born in a good condition. Except for one newborn who obtained nine APGAR points, all babies were given ten APGAR points.

The frequency of complications in mothers in our study did not demonstrate any apparent increase above that observed in pregnant women who did not receive VIT.

\section{Conclusions}

Pregnant women with a medical history of severe anaphylactic reactions after hymenoptera stings are at risk of potentially life-threatening reactions that result from insect re-stings. Self-injectable epinephrine, the current standard of treatment for anaphylaxis, also carries the risk of severe complications. Our studies have shown that VIT is safe for pregnant women and for infants.

\section{Conflict of interest}

The authors declare no conflict of interest.

\section{References}

1. Noon L. Prophylactic inoculation against hayfever. Lancet 1911; 1: 1572-1573.

2. Mueller UR. Insect sting allergy. Clinical picture, diagnosis and treatment. Gustav Fischer Stuttgart, New York 1990; 35-46.

3. Nittner-Marszalska M, Cichocka-Jarosz E, Małaczyńska T, et al. Safety of ultrarush venom immunotherapy: comparison between children and adults. J Investig Allergol Clin Immunol 2016; 26: 40-7.

4. Krishna MT, Huissoon AP. Clinical immunology review series: an approach to desensitization. Clin Exp Immunol 2011; 163: 131-46.

5. Bilò MB, Cichocka-Jarosz E, Pumphrey R, et al. Self-medication of anaphylactic reactions due to Hymenoptera stings - an EAACI Task Force Consensus Statement. Allergy 2016; 71: $931-43$

6. Ring J, Messmer K. Incidence and severity of anaphylactoid reactions to colloid volume substitutes. Lancet 1977; 1: 466-9.

7. Irani AM, AkI EG. Management and prevention of anaphylaxis. Version 1. F1000Res. 2015; 4: F1000 Faculty Rev-1492.

8. Nittner-Marszalska M, Liebhart J, Dor-Wojnarowska A. Sexrelated clinical aspects in insect venom anaphylaxis. Int J Immunopathol Pharmacol 2015; 28: 187-93.
9. Grabenhenrich LB, Dölle S, Moneret-Vautrin A, et al. Anaphylaxis in children and adolescents: the European Anaphylaxis Registry. J Allergy Clin Immunol 2016; 137: 1128-37.e1.

10. Oykhman P, Kim HL, Ellis AK. Allergen immunotherapy in pregnancy. Allergy Asthma Clin Immunol 2015; 11: 31.

11. Schwartz HJ, Golden DB, Lockey RF. Venom immunotherapy in the Hymenoptera-allergic pregnant patient. J Allergy Clin Immunol 1990; 85: 709-12.

12. Shaikh WA. A retrospective study on the safety of immunotherapy in pregnancy. Clin Exp Allergy 1993; 23: 857-60.

13. Braun CT, Mikula M, Ricklin ME, et al. Climate data, localisation of the sting, grade of anaphylaxis and therapy of hymenoptera stings. Swiss Med Wkly 2016; 146: w14272. 